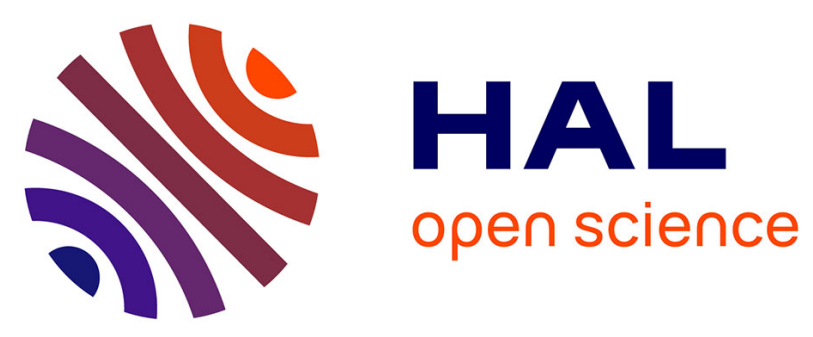

\title{
A new electro-optical transmission-line measurement-method revealing a possible contribution of source and drain contact resistances to GaN HEMT dynamic on-resistance
}

\author{
Dany Hachem, David Trémouilles, Frédéric Morancho, Gaëtan Toulon
}

\section{To cite this version:}

Dany Hachem, David Trémouilles, Frédéric Morancho, Gaëtan Toulon. A new electro-optical transmission-line measurement-method revealing a possible contribution of source and drain contact resistances to GaN HEMT dynamic on-resistance. Microelectronics Reliability, 2018, 88-90, pp.406410. 10.1016/j.microrel.2018.07.119 . hal-01893190

\section{HAL Id: hal-01893190 \\ https://hal.laas.fr/hal-01893190}

Submitted on 18 Oct 2018

HAL is a multi-disciplinary open access archive for the deposit and dissemination of scientific research documents, whether they are published or not. The documents may come from teaching and research institutions in France or abroad, or from public or private research centers.
L'archive ouverte pluridisciplinaire HAL, est destinée au dépôt et à la diffusion de documents scientifiques de niveau recherche, publiés ou non, émanant des établissements d'enseignement et de recherche français ou étrangers, des laboratoires publics ou privés. 


\title{
A new electro-optical transmission-line measurement-method revealing a possible contribution of source and drain contact resistances to GaN HEMT dynamic on-resistance
}

 \\ a LAAS-CNRS, Université de Toulouse, CNRS, UPS, Toulouse, France \\ ${ }^{\mathrm{b}}$ Exagan $\mathrm{SA}$, Grenoble, France
}

\begin{abstract}
Despite their potential in the field of power electronics, many reliability issues still affect the electrical performance of Gallium Nitride HEMT power devices and require an effort of analysis and understanding. The characterization of the on-state resistance of this transistor is necessary to understand the dynamics of some phenomena such as trapping. The degradation of this resistance has always been related to traps in the 2DEG channel, without taking into consideration possible contributions from the source and drain contacts (metal/semiconductor). In this work, resistance measurements, with and without UV illumination, are performed on three different technological options to highlight the effect of illumination on contact resistances.
\end{abstract}

Keywords - HEMT; Gallium Nitride; transmission line measurement; source and drain contact resistances; UV illumination; trapping phenomena; dynamic on-resistance.

\section{Introduction}

Gallium Nitride (GaN) high electron mobility transistors (HEMTs) are very promising devices for power applications thanks to the excellent properties of $\mathrm{GaN}$ (high critical electric field, high electron mobility and density in the 2DEG and high maximal operation temperature) that would allow to obtain high voltage, high temperature, high frequency and low losses power switches [1].

However, some phenomena remain not perfectly understood, like the trapping problems that affect the dynamic on-resistance of the component in the onstate and still require an effort of analysis and understanding. These trapping phenomena can be revealed by light or electrical excitation [2]. It has been shown that under UV illumination the conductivity of 2DEG in AlGaN/GaN HEMTs increases and a change in the drain current can be observed depending on the illumination. Several studies [3, 4] have linked the increase in 2DEG channel conductance to the change in state of charge at the surface level. Other studies [4, 5] have considered the absorption in the GaN buffer layer, but the photo-generated hole transport mechanisms in this region are not explained. In addition, it has been shown that the absorption of UV photons having energy higher than the bandgap of the $\mathrm{AlGaN}$ and the resulting gain is due to the generation of "photovoltages" (electron-hole separation) between the surface and the channel and the buffer/substrate interface and the channel [6].

To our knowledge, all the published papers, which deal with the dynamic on-state resistance, explain the effect by considering only the channel resistance, i.e. the resistance of the two-dimensional electron gas (2DEG) located in the GaN layer, in the vicinity of the $\mathrm{AlGaN} / \mathrm{GaN}$ interface, neglecting the effect of the source and drain (S/D) contact resistances that is however a significant contribution to the total device resistance. In this work, we studied the phenomena of on-resistance variation under UV excitation while considering both the resistance of the 2DEG channel and the source and drain contacts. Practically, the main objective of this work is not to study the dynamics of on-state resistance, but to disentangle the possible contribution of the contact region and the 2DEG region. To do this, we propose here a new Transmission Line Measurement (TLM) method to 
characterize the S/D contacts contribution.

We present the principles of our new ElectroOptical TLM (EO-TLM) method as well as the method of extraction of the contact resistance from the electrical characterization. Resistance measurements were performed in the dark and under UV illumination considering three different technological options.

\section{Characterization of the contacts using the TLM method}

The classical TLM method is a technique used to determine the contact resistance between a metal and a semiconductor [7]. Figure 1 schematizes an isolated TLM test pattern. This pattern is composed of several metal/semiconductor contacts of same dimensions, separated by different distances.

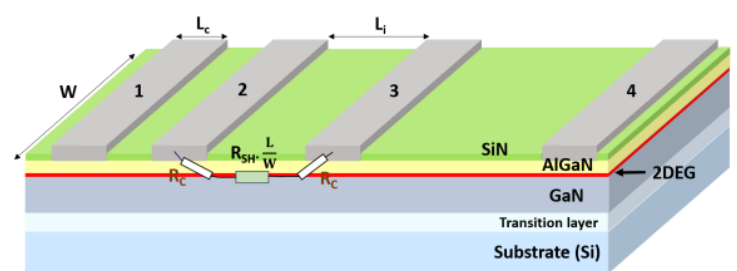

Fig. 1. Schematic section of a TLM characterization pattern and modelling of measured resistance between two consecutive contacts.

Figure 1 also shows the modelling of the resistance measured between two consecutive contacts. It can be considered that the total measured resistance $\left(R_{T}\right)$ is the sum of the resistances of the two contacts (expected equal and noted $R_{C}$ ) and the resistance of the 2DEG channel confined between the two semiconductors $\left(\mathrm{R}_{\mathrm{SH}}\right)$ (see Eq. 1).

$$
R_{T}=\left(R_{S H} / W\right)^{*} L_{i}+2 R_{C}
$$

\section{Choice of the used wavelength}

The central wavelength of the UV LED used is $393 \mathrm{~nm}$ (corresponding to $3.16 \mathrm{eV}$ photon energy). The full-width half-maximum (FWHM) of the LED is $13 \mathrm{~nm}$. Figure 2 presents the emission spectrum of this LED and shows that the corresponding photon energy is lower than the bandgap energy of $\mathrm{GaN}$, $\mathrm{SiN}$ and AlN (respectively in red, purple and green on Fig. 2). The used light therefore only affects the traps present in these materials and does not allow the direct generation of electron-hole pairs. As a consequence, we can obtain information related to the trap related phenomena of dynamic on-resistance that GaN HEMTs structures suffer from.

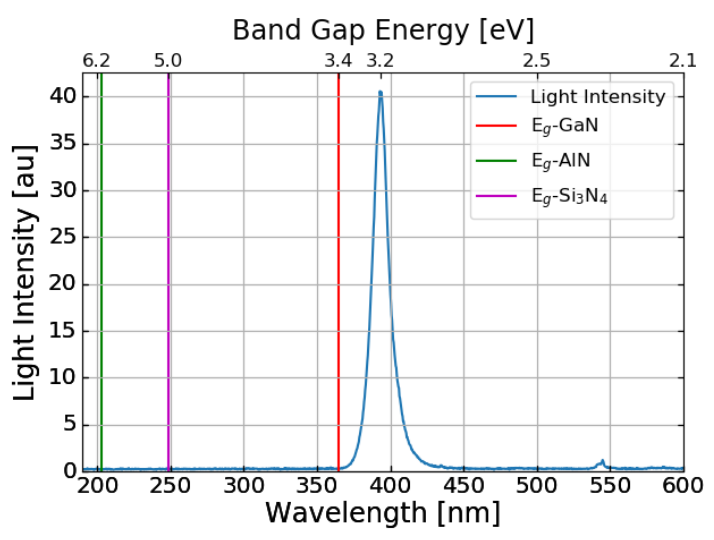

Fig. 2. Emission spectrum of the UV LED light used (blue), corresponding bandgap energy of: GaN (red), AlN (green), $\mathrm{Si}_{3} \mathrm{~N}_{4}$ (purple).



Fig. 3. Variations in the measured resistance as a function of time at several wavelengths. $\mathrm{R}_{0}$ represents value of the resistance in the dark. $\mathrm{V}_{\mathrm{TLM}}=200 \mathrm{mV}, \mathrm{T}=25{ }^{\circ} \mathrm{C}$, under an irradiance of few $\mu \mathrm{W} / \mathrm{cm}^{2}$.

The device under test was also exposed to a white lamp associated to a monochromator (with a $10 \mathrm{~nm}$ FWHM). The evolution of the resistance as a function of time after illumination-start for different wavelengths is shown in Figure 3. Light is turned-on at $\mathrm{t}=10 \mathrm{~s}$. We can see a decrease in the resistance value even with wavelengths higher than $393 \mathrm{~nm}$ (i.e. lower photon energy).

In addition, the refractive index of silicon is equal to 5.91 for a wavelength of $393 \mathrm{~nm}$ [8]. This index is less important for the other layers $(2.1,2.25$ and 2.6 respectively for $\mathrm{SiN}, \mathrm{AlN}$ and $\mathrm{GaN}$ ) [9-11]. A simple calculation, using Fresnel's equation (see Eq. 2), allows us to find that $16 \%$ of the light power at the transition layer/substrate interface will be reflected, with an incident angle $\theta_{i}=0.01^{\circ}$. These reflected rays can reach the bottom of the contacts. 


$$
R_{S}=\left|\frac{n_{1} \cos \theta_{i}-n_{2} \sqrt{1-\left(\frac{n_{1}}{n_{2}} \sin \theta_{i}\right)^{2}}}{n_{1} \cos \theta_{i}+n_{2} \sqrt{1-\left(\frac{n_{1}}{n_{2}} \sin \theta_{i}\right)^{2}}}\right|^{2}
$$

Furthermore, it can be assumed that the phenomena that lead to the resistance reduction are not related to the Si substrate layer. Indeed, in silicon that is a relatively low bandgap material, all photons are absorbed at the considered wavelengths and, as the irradiance actually increases with increasing wavelength in this setup, if the decrease in the resistance was related to the $\mathrm{Si}$ substrate the resistance should decrease even further for increasing wavelength. However, this is precisely the opposite that is observed. So the phenomena related to the resistance variation are assumed to take place in the layers of the wide bandgap materials.

\section{Extraction of the contact resistance}

In the first subsection, the differences between the measured samples will be shown. In the second one, we will present the principle of the extraction of contact resistance based on the EO-TLM method. Measurement results will then be detailed in the third subsection. The last subsection is dedicated to the comparison of the results obtained on three different technological options.

\subsection{Devices description}

Three samples of each technological option were measured. Figure 4 shows the difference between these technological options.

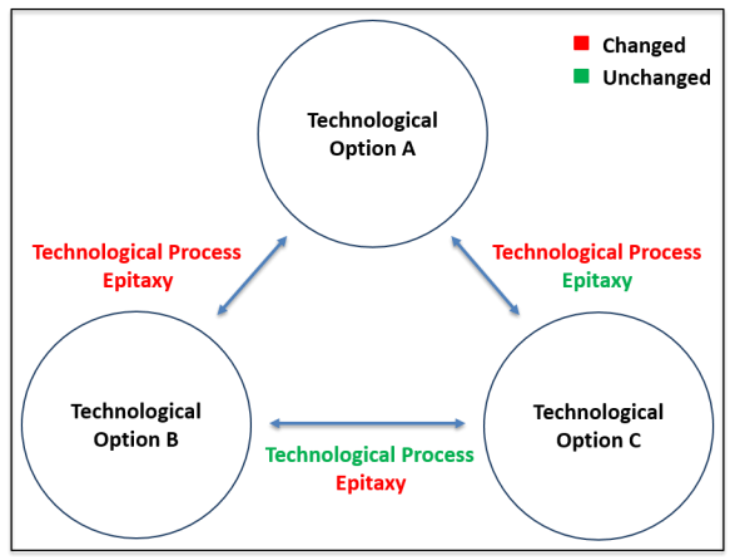

Fig. 4. Schematic illustrating the difference between the three technological options used in the study.

\subsection{Extraction method}

The application of a voltage between two consecutive TLM-structure contacts and the measurement of the resulting current allow calculating the resistance between these two contacts (while the silicon substrate is connected to the ground). This resistance must be extracted in the linear zone (non-saturated, i.e. where mobility is independent on the electric field) of the corresponding current-voltage (I-V) characteristic. Furthermore, for our EO-TLM method, the applied voltage must be chosen in the linear part of the I-V characteristic for all TLM distances. Figure 5 presents I-V characteristics of three samples with different technological options. The voltage used in the following measurements is $500 \mathrm{mV}$.



Fig. 5. I-V characteristics for three samples of each technological options, at $\mathrm{T}=25^{\circ} \mathrm{C}, \mathrm{L}_{\mathrm{i}}=4 \mu \mathrm{m}$. The selected voltage is $500 \mathrm{mV}$ for all following measurements (dashed red line).

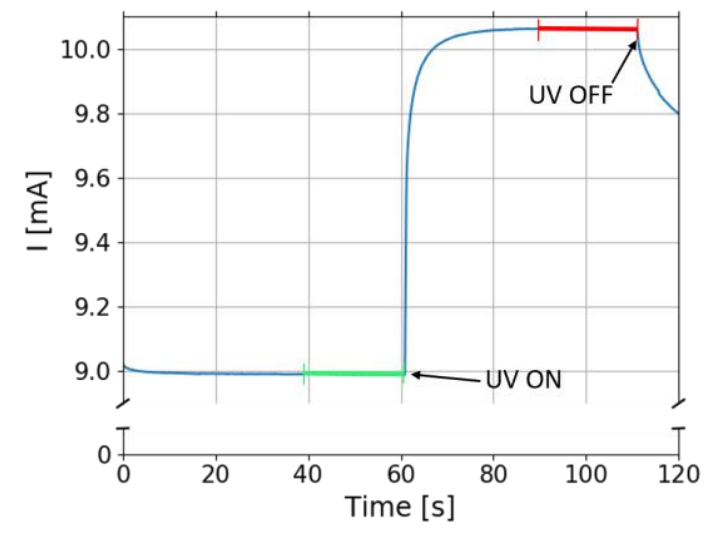

Fig. 6. I(t) curve used to calculate the two resistances in the dark (green bar) and under UV illumination (red bar) under an irradiance of few $\mathrm{mW} / \mathrm{cm}^{2}$, at $\mathrm{T}=25^{\circ} \mathrm{C}$, $\mathrm{V}_{\mathrm{TLM}}=500 \mathrm{mV}, \mathrm{L}_{\mathrm{i}}=16 \mu \mathrm{m}$.

Figure 6 shows an example of variation of the current measured as a function of time before, during 
and after illumination. In addition, this figure shows the parts of the curve used to extract the values of the two resistors, in the dark and under illumination, for a given distance $\mathrm{L}_{\mathrm{i}}$. The sample was globally exposed from the top to UV illumination for $50 \mathrm{~s}$ (from $t=60 \mathrm{~s}$ to $t=110 \mathrm{~s}$ ). It is necessary to wait for a sufficient long time (several hundred to a few thousand seconds), before starting the data extraction (coloured regions) so that the current is perfectly stable. Waiting for the current to stabilize is a critical point to obtain proper results.

\subsection{Measurement results}

Figure 7-a shows the results of the extraction of the resistances obtained with three TLM samples of technological batch A, with an applied voltage of $500 \mathrm{mV}$.
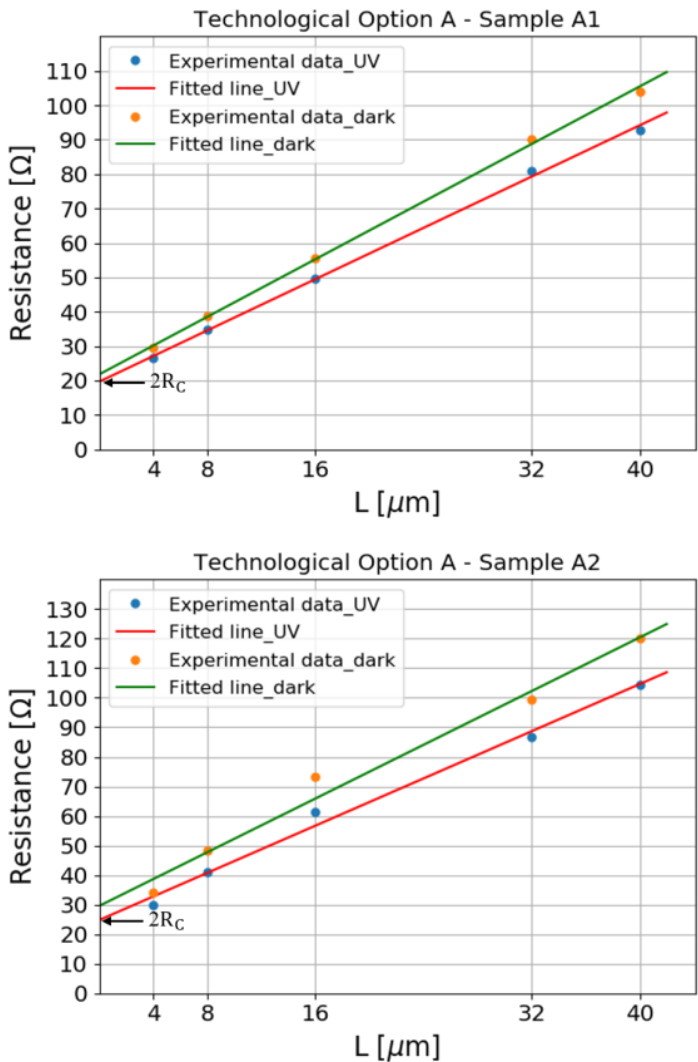

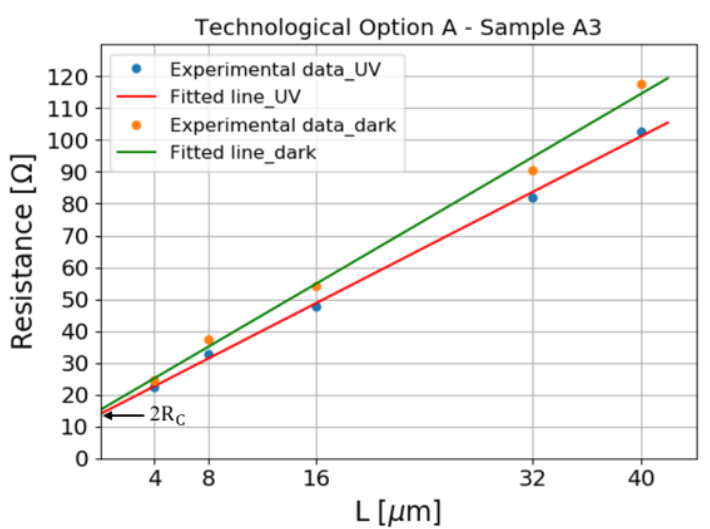

Fig. 7-a. $R(L)$ characteristics extracted, for 3 samples with the technological option $\mathrm{A}, \mathrm{V}_{\mathrm{TLM}}=500 \mathrm{mV}, \mathrm{T}=25^{\circ} \mathrm{C}$.

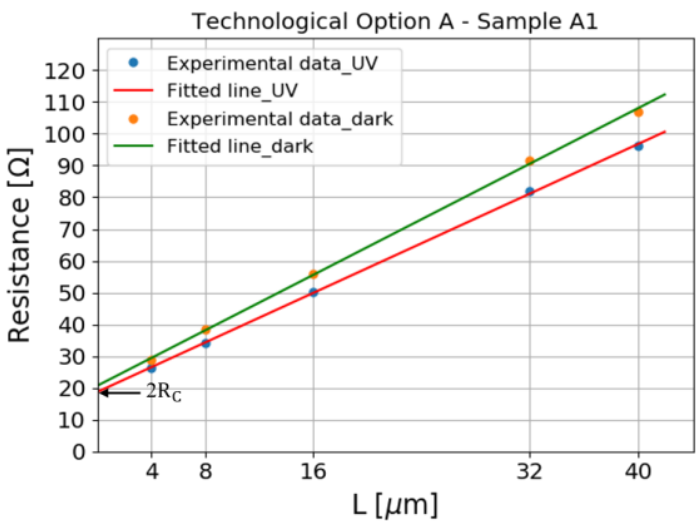

Fig. 7-b. $R(L)$ characteristics extracted, with a sample from the technological option A, IтLM $=20 \mathrm{~mA}, \mathrm{~T}=25^{\circ} \mathrm{C}$.

The orange and blue dots represent the total resistances for the different distances, extracted in the dark and under illumination respectively. The green and red lines correspond to the linear adjustment of the orange and blue dots respectively. The extension of the two lines obtained thus makes it possible to determine the resistance between two contacts separated by a zero distance $\left(\mathrm{L}_{\mathrm{i}}=0\right)$. The two values are halved in order to obtain the resistance of a single contact.

Using an identical voltage for all TLMresistance distances leads to the fact that the lateral electric field is actually decreasing with increasing distance. To keep the same electric field for all the distances of the TLM structure, a test with a current source has been carried out. In this configuration, the voltage across each resistance is measured, keeping the same precautions as for current measurement especially regarding voltage stabilisation. Figure 7-b shows the results obtained with an applied current of $20 \mathrm{~mA}$. The same behaviour was observed for 
constant-voltage and constant-current measurement configurations.

We carried out the same measurements on a structure with technological option B (change of epitaxy and the manufacturing process) (see Figure 4). A representation of the values of the resistances measured as a function of the distance between the electrodes is presented in Figure 8.
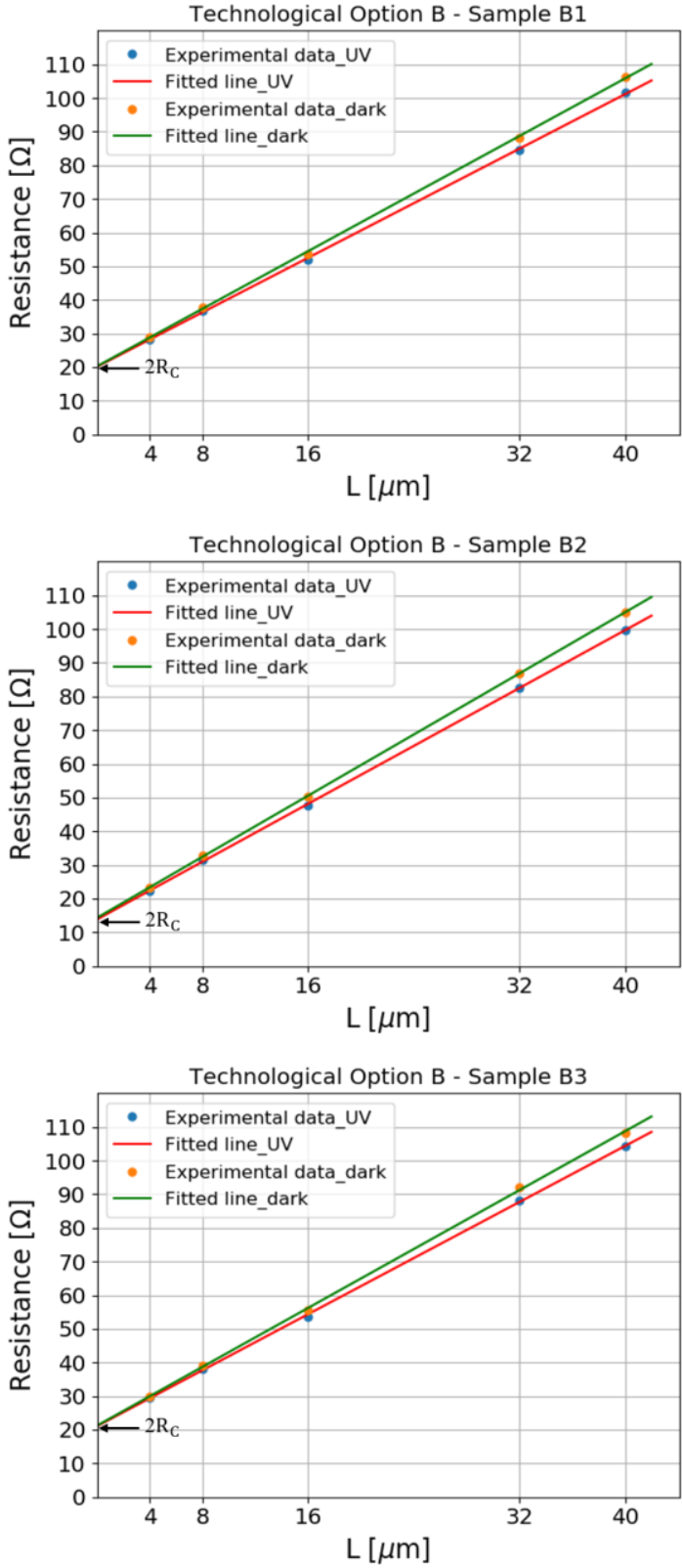

Fig. 8. $\mathrm{R}(\mathrm{L})$ characteristics extracted, for 3 samples with the technological option $\mathrm{B}, \mathrm{V}_{\mathrm{TLM}}=500 \mathrm{mV}, \mathrm{T}=25^{\circ} \mathrm{C}$.

\subsection{Comparison of the three technological options}

The results obtained with the three technological options are compared and discussed in the two following subsections.

\subsubsection{Comparison between $A$ and $B$}

The histogram of Figure 9 summarizes the values of the contact resistances, extracted from the $\mathrm{R}(\mathrm{L})$ characteristics of the different structures, with and without illumination, for three samples of each technological option.

With the technological option $\mathrm{A}$, we note that the difference between the values of the contact resistances, with and without illumination, is $\Delta \mathrm{R}_{\mathrm{C}}=12 \pm 4 \%$. This difference is much larger than that obtained with the technological option $\mathrm{B}$ $\left(\Delta R_{C}=0.9 \pm 0.2 \%\right)$, for which the effect of the UV is negligible on $\mathrm{R}_{\mathrm{C}}$.

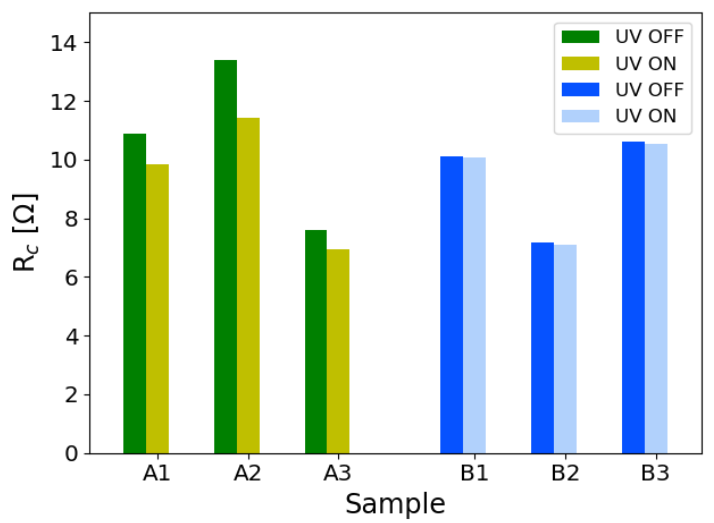

Fig. 9. Histogram showing the values of $\mathrm{R}_{\mathrm{C}}$, with and without illumination for the 6 samples of technologies A and $\mathrm{B}$ : with technological option $\mathrm{A}, \Delta \mathrm{R}_{\mathrm{C}}$ appears to be more much larger than that obtained with the technological option B.

\subsubsection{Comparison between $A, B$ and $C$}

To identify the parameter influencing the variability of the contact resistance under illumination, we carried out the same measurements on a third technological batch (technological option C). This batch was manufactured using the same technological process as the batch B and with a same epitaxial run as the batch A (see Figure 4). The histogram of Figure 10 compares the values of the contact resistances, with and without illumination, for the three technological options.

We can notice that the tested samples coming from the technological option $\mathrm{C}$ have the same behaviour as those of $\mathrm{A}$. So by changing the technological process, the effect of $U V$ on $R_{C}$ is 
always the same $\left(\Delta \mathrm{R}_{\mathrm{C}}=11.5 \pm 2 \%\right)$. We can deduce that the illumination effect on the contact resistance is most probably related to the epitaxy.

It is striking to note that the percentage of the contribution of the contact resistance variation to the total resistance is between $20 \%$ and $40 \%$. Table 1 summarizes the contact resistance values extracted from the $R$ (L) characteristics of all the tested samples. The ratio between the variations of the two contact resistances $\left(\Delta 2 R_{C}\right)$ and the total measured resistance $\left(\Delta \mathrm{R}_{\mathrm{T}}\right)$, for the samples of technological options that are sensitive to illumination, for $\mathrm{L}_{\mathrm{i}}=16 \mu \mathrm{m}$, is shown in the right column. This $\mathrm{L}_{\mathrm{i}}$ is representative of a source/drain distance required for a $600 \mathrm{~V}$ HEMT.

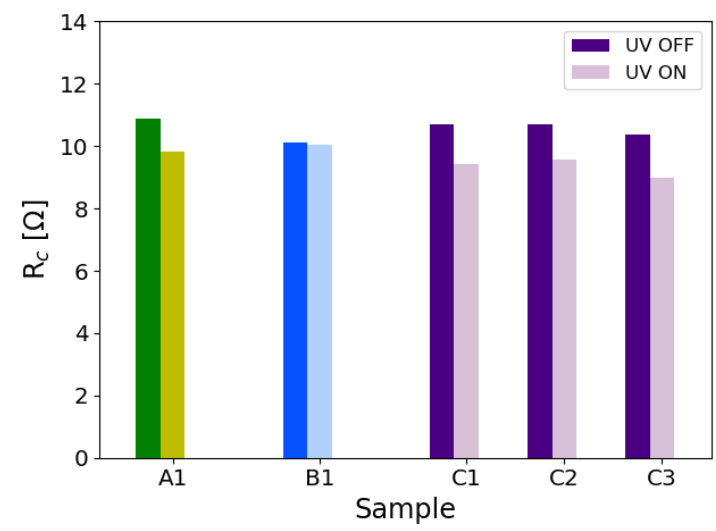

Fig. 10. Histogram showing the values of $R_{C}$, with and without illumination for some samples of technologies $\mathrm{A}$, $\mathrm{B}$ and $\mathrm{C}$ : the samples of technological option $\mathrm{C}$ exhibit the same behaviour as those of technological option $\mathrm{A}$ in terms of $\Delta \mathrm{R}_{\mathrm{C}}$.

Table1

Contact resistance values obtained from the $R(L)$ characteristics of the three technological options. Right column shows the ratio between the variations of the two contact resistances and the total resistance.

\begin{tabular}{|c|c|c|c|c|}
\hline Sample & $\begin{array}{c}2 \mathrm{R}_{\text {C_UV }} \\
(\Omega)\end{array}$ & $\begin{array}{c}2 \mathrm{R}_{\mathrm{C} \_d a r k} \\
(\Omega)\end{array}$ & $\begin{array}{c}\Delta 2 \mathrm{R}_{\mathrm{C}} \\
(\Omega)\end{array}$ & $\begin{array}{c}\Delta 2 \mathrm{R}_{\mathrm{C}} / \Delta \mathrm{R}_{\mathrm{T}} \\
(\%) \\
\mathrm{L}_{\mathrm{i}}=16 \mu \mathrm{m}\end{array}$ \\
\hline $\mathrm{A} 1$ & 19.69 & 21.81 & 2.12 & 35.8 \\
\hline $\mathrm{A} 2$ & 29.56 & 24.77 & 4.79 & 41 \\
\hline $\mathrm{A} 3$ & 13.91 & 15.2 & 1.29 & 20.8 \\
\hline $\mathrm{B} 1$ & 20.12 & 20.26 & 0.14 & $\mathrm{NA}$ \\
\hline $\mathrm{B} 2$ & 13.83 & 14.2 & 0.37 & $\mathrm{NA}$ \\
\hline $\mathrm{B} 3$ & 21.05 & 21.22 & 0.17 & $\mathrm{NA}$ \\
\hline $\mathrm{C} 1$ & 19.2 & 21.67 & 2.47 & 26 \\
\hline $\mathrm{C} 2$ & 17.97 & 20.75 & 2.78 & 21.5 \\
\hline $\mathrm{C} 3$ & 19.15 & 21.4 & 2.25 & 22.3 \\
\hline
\end{tabular}

\section{Conclusion}

The influence of UV illumination on metal/semiconductor contact resistances on $\mathrm{GaN}$ HEMT structures has been observed through the careful extraction of values from electrical measurement. The observed effect is more or less pronounced depending on the technology, demonstrating that the contact resistance is more or less sensitive to UV illumination. In worst cases, it is observed that from $20 \%$ up to $40 \%$ of the total resistance variation under illumination can be attributed to the contact resistance variation.

These results suggest that the dynamics of onstate resistance may be due not only to phenomena in the 2DEG channel but also to phenomena at the source and drain contacts. Therefore, it might be wise to verify the contribution of contacts using the method proposed here to ensure that an observed dynamic $R_{\text {on }}$ behaviour could be only related to physical effects affecting the 2DEG.

Finally, the measurement methodology proposed here is also interesting to detect process issues while being able to identify whether the problem is related to the contacts regions or the $2 \mathrm{DEG}$ channel.

As a perspective, the new proposed method gives also access to the dynamic evolution of the resistance after illumination is turned-on and after illumination is turned-off and possibly as a function of temperature and illumination wavelength. Proper treatment and analysis of this type of information is currently under investigation.

\section{Acknowledgements}

This work was supported by the LABEX GaNeX and the characterization platform of LAASCNRS.

\section{References}

[1] M. Meneghini et al., « Trapping and reliability assessment in D-mode GaN-based MIS-HEMTs for power applications », IEEE Transactions on Power Electronics, Vol. 29, №5, pp. 2199-2207, May 2014.

[2] T. Mizutani et al., «A study on current collapse in AlGaN/GaN HEMTs induced by bias stress », IEEE Transactions on Electron Devices Vol. 50, N ${ }^{\circ} 10$, pp. 2015-2020, October 2003.

[3] R. Vetury et al., « The impact of surface states on the DC and RF characteristics of AlGaN/GaN HFETs », IEEE Trans. Electron Devices 48, 560 (2001).

[4] Y-C. Chang, « Effects of illumination on the excess carrier dynamics and variations of the surface states in an $\mathrm{AlGaN} / \mathrm{GaN}$ heterostructure », J. Appl. Phys., vol. 107, no. 3, pp. 033706-1-033706-7, February 2010. 
[5] Y. Huang et al., « Photocurrent characteristics of twodimensionalelectron-gas-based $\mathrm{AlGaN} / \mathrm{GaN}$ metalsemiconductor-metal photodetectors », Appl. Phys. Lett., vol. 96, no. 24, pp. 243503-1-243503-3, June 2010.

[6] H. Zaidi et al., "Highly sensitive UV detection mechanism in AlGaN/GaN HEMTs », IEEE Transactions on Power Electronics, Vol. 60, $\mathrm{N}^{\circ}$, September 2013.

[7] W. Shockley et al., " Research and investigation of inverse epitaxial UHF power transistors », Air Force Atomic Laboratory, Wright-Patterson Air Force Base, USA A1-TOR-64-20, 1964.

[8] J. Šik et al. « Optical functions of silicon at high temperatures », J. Appl. Phys. 84, 6291-6298, 1998.

[9] K. Luke et al., " Broadband mid-infrared frequency comb generation in a $\mathrm{Si}_{3} \mathrm{~N}_{4}$ microresonator », $\mathrm{Opt}$ Lett. 40, 4823-4826, 2015.

[10] J. Pastrňák et al., « Refraction index measurements on AlN single crystals », Phys. Stat. Sol. 14, K5-K8, 1966.

[11] A. S. Barker Jr. et al., «Infrared lattice vibrations and free-electron dispersion in GaN ». Phys. Rev. B 7, 743-750, 1973. 